\title{
A case study: Obesity and the metabolic syndrome. A three- pronged program, targeting education, close follow-up and a dietary supplement, significantly decrease body weight and body fat
}

\author{
Grethe S Birketvedt ${ }^{1 *}$, Carl Fredrik Schou ${ }^{2}$ and Erling Thom ${ }^{3}$ \\ ${ }^{1}$ Medical Center for Obesity and Research, Baerum, Oslo, Norway \\ ${ }^{2}$ Teres Colosseum, Oslo, Norway \\ ${ }^{3}$ ETC Research and Development, Oslo, Norway
}

\begin{abstract}
A 38-year old woman with a body fat content of $52.2 \%$ and a BMI of $48.2 \mathrm{~kg} / \mathrm{m}^{2}$ was seeking medical treatment in an outpatient obesity clinic in Oslo, Norway. She suffered from a severe abdominal hernia and was not qualified for surgery of this condition until her BMI was under $30 \mathrm{~kg} / \mathrm{m}^{2}$. Additionally, she was severely challenged in terms of mobility as she was born with cerebral palsy and required either a wheel chair or crutches to get around. Over the years she had sought several treatment options to control her obesity but with no success. She did not qualify for bariatric surgery and was severely depressed when she came to the clinic. After examination and diagnosis, the decision was made to begin a multi-pronged treatment using a natural dietary supplement, combined with the customized educational program called "The Body in the Brain", and a close medical follow-up with regular appointments to the outpatient clinic. After twenty-three months of treatment, the woman had lost $38 \mathrm{~kg}$ of bodyweight and had normalized fat percentage for her age and gender. In conclusion, it is possible to successfully treat severe obesity and return a patient to a normal body fat percentage with the combination of a natural dietary supplement, a designed diet composition and a weight loss behavioral program.
\end{abstract}

\section{Introduction}

Obesity and the metabolic syndrome are linked together [1]. When an individual gets severely obese, insulin resistance, hypertension and increased abdominal circumference follow as a natural cause due to the excess fat in the body. Obesity and the metabolic syndrome has been extensively researched and today clinical evidence implicates intra-abdominal adiposity as a powerful driving force for elevated cardio metabolic risk [2]. This association appears to arise directly, via secretion of adipokines, and indirectly, through promotion of insulin resistance.

The most important therapeutic intervention effective in subjects with the metabolic syndrome should focus on weight reduction and regular daily physical activities. Health experts agree that making lifestyle changes, including following a healthy eating pattern, reducing caloric intake, and engaging in physical activity, are the basis for achieving long-term weight loss [3,4]. However, weight-loss and weight-management regimens have frequently been ineffective. Therefore, effective medical interventions to manage weight gain and slow or prevent progression to obesity are needed. Control of diet and exercise are cornerstones of the management of excess weight. A number of nutritional approaches and diets with different proportions of lipids, proteins and carbohydrates have been prescribed for weight loss. Initial guidance on weight loss was earlier years a restriction in saturated fats that unfortunately did not necessarily result in weight loss. Recently, a shift towards a reduction in refined carbohydrates has been a new approach to lose weight.

Several studies have indicated that fiber-rich foods and fiber supplements have moderate weight reducing effects, and may also improve the lipid profile in overweight and obese individuals $[5,6]$. There are hundreds of weight loss products sold over the counter today. Typically, these OTC supplements have not been clinically tested, can have significant unwanted side effects and not yield successful results in helping people to lose weight.

The natural product, used in this case study is supplement that consists of a unique combination of three natural ingredients: white kidney bean extract, locust bean gum extract and green tea extract that affect weight loss with little to no side effects. The white kidney bean extract is phaseolus vulgaris, a bean extract containing phaseolamin. Phaseolamin is a glycoprotein found mainly in white and red kidney beans and is an effective alfa-amylase inhibitor [7]. The extract of locust bean gum, is a seed-coat extract that decreases ghrelin [8], the hunger

Correspondence to: Grethe S Birketvedt, Medical Center for Obesity and Research, Baerum, Oslo, Norway; E-mail: gsb42nor@aol.com

Key words: obesity, weight loss, metabolic syndrome

Received: January 12, 2016; Accepted: February 08, 2016; Published: February 11,2016 
Birketvedt GS (2016) A case study: Obesity and the metabolic syndrome. A three-pronged program, targeting education, close follow-up and a dietary supplement, significantly decrease body weight and body fat

hormone and make you feel faster satiated and will postpone the hunger sensation after a meal. Locust bean gum has also shown lipid lowering effects in several studies [9]. The third ingredient is a green tea extract [10-12], Camellia sinensis with anti-inflammatory and antioxidant properties with a small increase in the energy expenditure.

\section{Aim of study}

The aim of this study was to investigate whether a dietary supplement with white kidney bean extract, locust bean gum extract and green tea extract in combination with a program with lifestyle changes would enhance weight loss and fat loss and improve the metabolic parameters in a severe obese patient with the metabolic syndrome.

\section{Methods}

\section{Patient}

A 38 year old woman with a history of obesity, diabetes type 2 and hypertension was seeking treatment in an out-patient clinic in Oslo, Norway for medical weight loss management. She was well aware of the link between obesity, diabetes and cardiovascular disease and felt this appointment she had asked for was her last chance in getting help with her health problems.

She had been normal weight as a child and adolescent, but do to a dependency of crutches and a wheelchair she had gradually put on weight in her twenties. She was married with two young children and she increased in weight after each child birth. She suffered a severe abdominal hernia that stressed her, but she had been refused surgery due to her heavy weight.

She had in her childhood and teens always been of normal weight, active and healthy in spite of her physical disabilities. When she got married, she gradually gained weight and the weight culminated after her second child was born. She had developed diabetes type 2 and hypertension after her children were born, and was medicated with antihypertensive and antidiabetics. Her primary care physician had not really been interested in her weight and had several times suggested higher doses of medications or insulin injections. The patient was not interested in insulin injections as she was afraid of gaining more weight.

Our patient had been sedentary the last 5 years due to the abdominal hernia. She had tried many weight loss efforts on her own, had started working with a personal trainer and had weekly sessions with a physical therapist. Her diet had been high in fat and calories although she was very well educated in nutritious food. However, she admitted to overeating, and periods of binging. She drunk about 2.5 liter of diet soda a day including diet juice. She was very conscious about eating habits when it came to her two kids, and they were both healthy and in normal weight. She had a university education and was well informed of her health situation. But she was under much stress in her daily life and struggled daily to get help from health authorities.

Her initial anthropometric measurements included a weight of $125 \mathrm{~kg}$ with a height of $1.61 \mathrm{~m}$, a body mass index (BMI) of $48.2 \mathrm{~kg} /$ $\mathrm{m}^{2}$ which classified her as morbidly obese. Her fat \% was $52.2 \%$ with $65 \mathrm{~kg}$ fat mass measured by bioelectrical impedance analysis (BIA) [13] (Tanita Body Composition Analyzer BC-418) for analyzing the composition of the body, such as weight, lean body mass (LBM), total body water (TBW), fat free mass (FFM) and basal metabolic rate (BMR). Her HbAlc had the last 2 months ranged from $11.7 \%$ till $8.8 \%$ and her hypertension was 160/95 $\mathrm{mm} \mathrm{Hg}$.

\section{Informed consent}

The patient has signed and approved the consent form.

\section{Management}

On the first visit to our clinic, the patient was advised of which food items of simple carbohydrates she should try to avoid in her daily diet. She was given restrictions in caloric content and a diet plan, specifically designed for her health situation with emphasis on her hypertension and diabetes type 2 . She was also advised to drink water with a slice of lime instead of diet sodas and diet juice. One of her main goals was to be able to not require medications for control of her hypertension that would then improve her diabetes type 2 and simultaneously decrease her weight. It was extremely important for the treating physician to give her food compositions that targeted the ability to relieve stress in the gut-brain axis.

Her resting metabolic rate (RMR) was measured to $1828 \mathrm{kcal}$ and the physician designed a diet in the range of $1200 \mathrm{kcal}$ to $1600 \mathrm{kcal}$. In that way, she at least could have a deficit of about $400 \mathrm{kcal}$ a day taking into account her limited physical activity level. In a two week period this regimen would theoretically allow her approximately a $0.5 \mathrm{~kg}$ loss in weight. Due to her decrease in simple carbohydrates she was advised to check her blood sugar 3 times per day and write the recordings down until next meeting. She was instructed on how to decrease her diabetes medication based on her blood sugar levels.

The weight management program at our clinic was continuing with bi-weekly visits by the patient for the next six weeks, and then monthly visits after that time. Furthermore, the patient was advised after six weeks to additionally take one capsule of the dietary supplement twenty minutes before each of the main meals, breakfast, lunch and dinner.

On a monthly basis, her weight and body fat percentage were recorded with BIA at the doctor visits. Moreover, she was given 1 hour consultation with behavioral modification with advise to lifestyle changes according to a program entitled the "Body in the Brain", a recently published book in Norway, targeting education on how the brain and the body work together in hormonal harmony when the right diet is introduced for the right person. The patient was allowed to eat whatever she wanted in the diet plan restricted to $1200-1600$ $\mathrm{kcal}$, excluded from the carbohydrate list were white breads and pasta, cookies, cake, candy, sugar-sweetened sodas and drinks as well as diet sodas and diet juice. She followed the educational program related to the "Body in the Brain" [14] where she each month was given new insight into how the body and the brain worked together in a hormonally balanced way. She was also gradually introduced to healthier foods, e.g., food that was rich in tryptophan, an essential amino acid that target serotonin in the brain and indirectly impact insulin levels. In her diet plan was a list of tryptophan rich food such as e.g.salmon, chicken, cod, tuna, apricots, broccoli, sprouts, whole grain, skimmed milk and almonds, food that was known as comfort food or mood food. The list was extended each visit and the food the patient did not like was replaced with other food items.

\section{Results}

In her first two weeks of treatment she lost only one pound, but she reported that her blood sugar had not spiked as much as prior times after she had tried to avoid sugar and other simple carbohydrates. She admitted it was difficult to avoid these foods as she always had had a sweet tooth. On her second visit she was educated in how the body relates to the brain in a hormonal way when certain food items are 
Birketvedt GS (2016) A case study: Obesity and the metabolic syndrome. A three-pronged program, targeting education, close follow-up and a dietary supplement, significantly decrease body weight and body fat

ingested. She was introduced to the amino acid tryptophan and how the tryptophan rich food would create more harmony in the gutbrain axis, increase serotonin levels and decrease cortisol and thereby improve insulin sensitivity. The education went on for 22 months and at each visit the biochemistry of food were addressed. How the food she ingested had an impact on her body and brain was a favorite topic of the visits to come.

Over the next four weeks she had lost only $1.2 \mathrm{~kg}$. The visit two weeks later showed a decrease of an additional $0.7 \mathrm{~kg}$, however the fat percentage in her body had not changed. Until this time, the fat lost was attributable to pure lean body mass. She was then introduced to the patented supplement consisting of Green tea extract, White kidney bean extract and Locust bean gum extract, a supplement that was sold over the counter in Norway, approved by the Norwegian Medicines Agency and also recently the ingredients were approved by the FDA in the US. She gradually lost weight each month with a simultaneous loss in fat percentage. 12 months later she had lost $21 \mathrm{~kg}$ of which $85 \%$ was loss in fat mass. She became less depressed, her energy level had improved, and she was still very motivated for further weight loss.

By the end of the 23 month treatment period she had lost $38 \mathrm{~kg}$ and the fat percentage in the body had decreased to $31.9 \%$ which was within normal limits for her age. Her blood sugar was under control. However, she was still on antidiabetics, however, her blood sugar and HbAlc was within normal limits and her hypertension was well regulated. Six months later, she was accepted for the surgery of her abdominal hernia as her fat mass was within normal range in spite of a BMI $>30 \mathrm{~kg} / \mathrm{m}^{2}$.

\section{Discussion}

The patented diet supplement with white kidney bean extract, locust bean gum and green tea extract in combination with an education program (The Body in The Brain) consisting of twenty-six outpatient clinic sessions, resulted in a very significant weight loss, improvement in fat percentage, hypertension and blood sugar levels in an obese woman following this program. In terms of the weight loss observed in this patient, fat was more than $75 \%$ of the total weight lost indicating a qualitative weight reduction where less than one quart of the weight lost was lean body mass[15]. The patient lost $25 \%$ more body fat of her weight lost than would predicted with lifestyle changes alone. The special designed diet program was modified accordingly in subsequent visits due to changes in the BMR. Her caloric intake was never changed to lesser than her BMR. The reason why her energy level increased and her mood improved, can very well be caused by the change in diet., At each meal, she ate primarily foods rich in tryptophan combined with complex carbohydrates and thereby increased her serotonin levels. Several studies have shown that increased serotonin levels are related to mood elevations $[16,17]$. However, her improved mood and higher energy in this patient, may also be caused by the fat lost relieving the stress in the gut-brain axis.

The amount of fat mass lost of weight lost was far more than reported in earlier studies. This is in accordance with earlier unpublished pilot studies with the diet supplement used in this case report. We believe that adding this specific supplement to this combined treatment enhanced fat loss and thereby normalized parameters associated with the metabolic syndrome. Earlier studies have shown that in severe obese individuals it is almost impossible to reach normal fat mass with lifestyle changes and behavioral modification alone. We believe that our natural supplement had both carbohydrate and lipid lowering effects on fat metabolism and also increased the fat expenditure. Moreover, we believe that the education program, The Body in the Brain used in this three-pronged program, enhanced the weight loss. The patient understood the mechanisms in her body related to the food she ate, which increased her motivation for weight loss and prevented weight gain again as in earlier reports. Moreover, an encouraging physician at each visit may also be important for the patient to reach her goals. We cannot neglect the fact that obese patients are very sensitive to the knowledge of the physician and the way she is being encouraged on her road to weight loss.

A program like this can be a valuable method in the treatment of obesity in the future.

\section{Conclusion}

A three-pronged treatment paradigm that includes close physician follow-up, a well designed education program, and the addition of a dietary supplement consisting of an extract of white kidney bean, an extract of locust bean gum and an extract of green tea extract gave a substantial weight loss and a loss in fat mass towards a normal fat percentage in a severe obese person with the metabolic syndrome.

\section{References}

1. Després JP, Lemieux I (2006) Abdominal obesity and metabolic syndrome. Nature 444: 881-887. [Crossref]

2. Scheen AJ (2004) Management of the metabolic syndrome. Minerva Endocrinol 29 31-45. [Crossref]

3. Pittler MH, Ernst E (2004) Dietary supplements for body-weight reduction: a systematic review. Am J ClinNutr79: 529-536. [Crossref]

4. Jensen MD, Ryan DH, Apovian CM, Ard JD, Comuzzie AG, et al. (2013) AHA/ACC TOS guideline for the management of overweight and obesity in adults: a report of the American College of Cardiology/American Heart Association Task Force on Practice Guidelines and The Obesity Society. Circulation: 1- 63.

5. Birketvedt GS, Aaseth J, Florholmen JR, Ryttig K (2000) Long-term effect of fibre supplement and reduced energy intake on body weight and blood lipids in overweight subjects. Acta Medica (Hradec Kralove) 43: 129-132. [Crossref]

6. Birketvedt GS, Langbakk B, Florholmen J (2004)A Dietary Supplement with Bean Extract Decreases Body Weight, Body Fat, Waist Circumference and Blood Pressure in Overweight and Obese Subjects. Current Topics in Nutraceutical Research 3: 137-142.

7. Preuss HG (2009) Bean amylase inhibitor and other carbohydrate absorption blockers effects on diabesity and general health. J Am Coll Nutr 28: 266-276. [Crossref]

8. Gruendel S, Garcia AL, Otto B, Mueller C, Steiniger J, et al. (2006) Carob pulp preparation rich in insoluble dietary fiber and polyphenols enhances lipid oxidation and lowers postprandial acylated ghrelin in humans. J Nutr 136: 1533-1538. [Crossref]

9. Zavoral JH, Hannan P, Fields DJ, Hanson MN, Frantz ID, et al. (1983) Thehypolipidemic effect of locust bean gum food products in familial hypercholesterolemic adults and children. Am J Clin Nutr 38: 285-294. [Crossref]

10. Toda (1989) Green tea extract has been shown to decrease weight in overweight subjects. Nippon SaikingakuZasshi 44: 669-672.

11. Dulloo AG, Duret C, Rohrer D, Girardier L, Mensi N, et al. (1999) Efficacy of a green tea extract rich in catechin polyphenols and caffeine in increasing 24-h energy expenditure and fat oxidation in humans. Am J Clin Nutr 70: 1040-1045. [Crossref]

12. Wolfram S (2007) Effects of green tea and EGCG on cardiovascular and metabolic health. J Am Coll Nutr 26: 373S-388S. [Crossref]

13. Böhm A, Heitmann BL (2013) The use of bioelectrical impedance analysis for body composition in epidemiological studies. Eur J ClinNutr 67 Suppl 1: S79-85. [Crossref]

14. Birketvedt GS (2008) The Body in the Brain. Editor XLibriz, Norway. 280 p Norwegian language. In press for English translation.

15. Heymsfield SB, Gonzalez MC, Shen W, Redman L, Thomas D (2014) Weight los composition is one-fourth fat-free mass: a critical review and critique of this widely cited rule. Obes Rev 15: 310-321. [Crossref] 
Birketvedt GS (2016) A case study: Obesity and the metabolic syndrome. A three-pronged program, targeting education, close follow-up and a dietary supplement, significantly decrease body weight and body fat

16. Benton D, Donohoe RT (1999) The effects of nutrients on mood. Public Health Nutr 2: 403-409. [Crossref]

17. Ottley C (2000) Food and mood. Nurs Stand 15: 46-52. [Crossref]

Copyright: $(02016$ Birketvedt GS. This is an open-access article distributed under the terms of the Creative Commons Attribution License, which permits unrestricted use, distribution, and reproduction in any medium, provided the original author and source are credited. 